DOI: 10.14526/2070-4798-2020-15-2-85-91

\title{
About the indices of subjectivity demonstration among the athletes in the aspect of structure and content of self-attitude specificity
}

\author{
Valentin V. Kuznetsov*, Svetlana N. Tregubova \\ Chaykovskiy State Institute of Physical Culture \\ Chaykovskiy, Russia \\ ORCID: oooo-0001-6067-0848, d.inga@inbox.ru* \\ ORCID: oooo-ooo3-1555-6311, lana20016@yandex.ru
}

\begin{abstract}
The urgency of the research is in the fact that a modern person has a distinct need for the opportunity to demonstrate personal self-realization and subjective activity. The aim of the research work is to realize comparative analysis of self-attitude among athletes, who go in for athletic kinds of sport and fighting (martial) arts. Materials and Research methods. 76 people took part in the research work: students-athletes and people, who go in for fighting combats, who were divided into two groups: control group $(C G, n=41)$ and the main group (MG, $\mathrm{n}=35$ ). Results. We considered the research results according to some kinds of scales. Scale I: openness- closedness. The results of statistic hypothesis check concerning the independence of the features (the level of psychological "openness" and sports specialization) proved that the differences between the results of two groups were statistically valid $(p=0,001)$. Students-athletes showed more open attitude to themselves. Scale II: self-confidence. Statistical hypothesis check about the independence of the features (sports specialization - self-confidence) showed that in results distribution differences have statistically valid character $(\mathrm{p}=0,05)$. Conclusion. As a result of the held qualitative analysis of athletes' answers we described psychological content of different aspects of self-attitude. If we consider the parameter of self-confidence in the group of athletes, in terms of self-estimation (according to the frequency of affirmative answers) the first place they gave to reliability and self-respect and the representatives of fighting combats- the ability to place responsibility on oneself and make decisions in difficult situations. Subordinate factors analysis showed that in the athletes, who go in for fighting combats, prevails productive structure of self-attitude. Thus, this group is characterized by high indices of self-respect. The basis of it form high self-estimation of athletes according to socially important criteria. If we speak about low indices of "self-destruction", taking into account that they are received in terms of high argumentation, we can mention that they prove psychological correspondence between different aspects of outer and inner life of athletes, who go in for fighting combats.
\end{abstract}

Keywords: self-attitude, fighting combats, athletic kinds of sport, openness-closedness, selfconfidence, self-management, reflected self-attitude.

For citation: Valentin V. Kuznetsov*, Svetlana N. Tregubova. About the indices of subjectivity demonstration among the athletes in the aspect of structure and content of self-attitude specificity. Russian Journal of Physical Education and Sport. 2020; 15(2): 69-73. DOI: 10.14526/2070-4798-2020-15-2-85-91

\section{INTRODUCTION}

The urgency of the present research is in the fact that a modern person has distinct need for the ability to show personal self-realization and subjective activity [1].

The aim of the psycho-diagnostic research is comparative analysis of self-attitude in athletes, who go in for athletic kinds of sport and fighting (martial) arts.

During the research the following objective was solved: to reveal distinctive-style structures of self-attitude and activity of different sports specializations athletes.

\section{MATERIALS AND METHODS}

Psycho-diagnostic study of self-attitude among athletes of different specializations was held among 76 boys -who go in for fighting combats (MG, $\mathrm{n}=35$ ), and students of the $3^{\text {rd }}$ course of Physical Culture and Sport Institute UdSU, Russia (CG, $n=41$ ). In order to handle the results we used sports specialization index in the group of students, as they were divided into sports departments and went through the process of selection. We should mention 
that chosen sports specializations were athletic kinds of sport: $32 \%$ of students chose sports games 17\%- gymnastics, $19 \%$ - skiing, 32\% - track and field athletics.

For psycho-diagnostic self-attitude study we used the methodology by S.R. Pantileev [5]. As the measure of the first points standardization by the authors of the questionnaire was used the sten scale. Quantitative analysis of the received results was held with the following normalization: standard deviation $-2,5$ stens; median $-5,5$ stens; average values zone (don't have valid diagnostic predictive value) - from 4 till 6 stens inclusively; high values zone- from 7 till 10 stens inclusively; low values zone- from 1 till 3 stens inclusively.

For mathematical-statistical analysis we used contingency table and nonparametric $\chi^{2}$ -criterion for psycho-diagnostic research results description [2;4]. For the qualitative analysis we used such questions of the separate scales, the answers to which can be characterized by high consistency inside the group.

\section{RESULTS AND DISCUSSION}

Let's consider the research results according to some scales.

Scale I: openness- closedness. This scale has the statements, which define negative qualities of a person (from the positions of morality). In this connection the respondent had to show the definite level of courage and inner honesty. In the opinion of the questionnaire author, this factor helped to define the predominance of one of the tendencies - either the motivation of social approval (high values) predominance, or inner honesty (low values according to the scale).

The received results were distributed in both groups in the zone of high and average values. The results of checking statistical hypothesis concerning features independence (the level of psychological "openness" and sports specialization) proved, that the differences between the results of two groups were statistically valid ( $\mathrm{p}=0,001)$. Students-athletes showed more open attitude to themselves. In terms of the author's interpretation, this is reflexivity index of behavioral demonstrations and own "Self" realization. $12 \%$ of boys from this group have closed attitude to themselves. The results of the most part of the group (68\%) are less than the sampling median. It proves inner honesty tendencies and sociability prevalence.

The results received in the group of athletes, who go in for fighting combats (main group), prove the doubt concerning the informativity of this scale for people, who want to leave in accordance with eastern religions ethic principles and norms, which these religions (Buddhism and Confucianism) proclaim. In this case some qualities negation can be considered both as social-normative model of a modern combatant ideal "Self" or so called Ethics Code and as the index of social desirability and not developed reflection motive dominance.

Scale II: self-confidence. The questions of this scale define the attitude toward oneself as a reliable, confident and independent person. In the opinion of the author, for this scale the answers for these questions were conditioned by a person's general self-affirmation. The content of the questions is directed toward the following things diagnostics: ironic attitude to oneself; self-affirmation; energy; purposefulness and the ability to realize the ideas; social flexibility and communicativeness; reliability; readiness to accept responsibility in solving difficult situations; control over own fortune.

The received results showed high values prevalence in the control group (46\%) and the main group (74\%). Checking statistic hypothesis about the features independence (sports specializationself-confidence) showed, that in results distribution the differences had statistically valid character $(\mathrm{p}=0,05)$.

On the basis of the fulfilled qualitative analysis we can say that we revealed different content of self-confidence as a psychological trait among the representatives of the students group and among the representatives of the main group. Most students from the control group (CG) have self-respect and reliability (93\%).

System forming qualities of self-confidencein the main group became the ability to make decisions in difficult situations and take responsibility (94\%), social reliability (94\%) and purposefulness (94\%), and only $38 \%$ of respondents of the mentioned group proved their capacity to self-irony. 
Scale III: self-management. For this scale the notion of a person that "the main source of activity and effectiveness, both in activity and own person of a subject, is a person himself" is typical [5, p. 14]. According to this scale high values correspond with the opinion of an individual about own abilities to influence the opinion of people concerning himself; control own fate and situations in it; cope with the emotions concerning oneself. In general the considered factor of self-attitude, as underlines the author of the questionnaire, influences subjective sense of controllability and predictability of own "Self".

The results, received during the research, and a statistical check of the hypothesis concerning the features independence prove statistically valid differences between the groups, dominance of high indices of self-management in the main group $(\mathrm{p}=0,05)$.

In order to define the main personal essences, which are formulated with the help of the emotions language, for athletes' answers qualitative analysis, the questions of the scale were divided into two groups:

I - control over oneself and own emotions;

II - subject's influence on the opinion of people about himself.

The results show the differences both in the structure of this quality and at the levels of the separate self-management indices (as psychological traits of personality in athletes of two considered groups). In the group of athletes, who go in for fighting combats, self-management, own development, emotions concerning oneself management took the first place. The opinion of people for athletes from this group is not accident - it is controlled and corresponds with their own opinion about themselves. It should be noted that for the combatants, as the representatives of a martial art, the events in their life, as a rule, are "the objectives for examination". They correspond with the level of their development as combatants. In these events they take part as the values, equal to the happening one $[8,9,10,11,12,13,14]$.

The results, shown in the group of students, have another structure - the only one controlled subject for a student-athlete is himself and his own emotions. The events in his life, the same as the opinion of people about him, don't have controlling abilities for this individual. That is why if in terms of themselves and their abilities athletes-students are subjects, then in the sphere of event and social relations they are more objects of what is happening, than subjects. In other words "something" is happening to them in life and people around think something" of them.

Scale IV: reflected self-attitude. In terms of this scale we held the diagnostics of the subject's notions of the feelings that his personality, character and activity are able to arouse among other people (positive or negative). The author of the questionnaire pays attention to the fact that we speak about the anticipated or supposed attitude. One of the important explanations of self-attitude, which conditions subject's vulnerability and social sensitivity, is the expected attitude of other people to themselves [9].

Statistical hypothesis about the independence of the features (kind of sports specialization-reflected self-attitude) was proved. We received one and the same character of indices of the reflected self-attitude distribution in both groups. Nevertheless, as the qualitative analysis of the answers showed, psychological basis of the reflected self-attitude in two groups are different.

The answers analysis, fulfilled by us in the main group, showed the dominance of social attitude positive anticipation to oneself $-83 \%$ of respondents were negative answering the question: "It is extremely unlikely that there are people, who don't like me", $77 \%$ of respondents of the group mention that acquaintances appreciate them and take them seriously; $74 \%$ of the respondents don't lack understanding and close people. Thus, the reflected self-attitude in the main group has rationally substantiated origin [3].

In the control group answers to some questions contradict each other. $88 \%$ of students think that a stranger would consider them a pleasant man. At the same time, 73\% don't reject that their personality has something that is able to cause negative emotions in other people. Such contradictions prove emotional component dominance in the reflected self-attitude formation 
in athletes-students. The result of it is instability, which decreases general tolerance towards unfavorable social influences [3].

The next stage of comparative-psychological analysis provided the necessity to present the received results according to 9 scales in the aspect of three factors-modalities, defined by S.R. Pantileev. "It helps to transfer from the differentiated picture of self-attitude description to integrative complexes of thoughts and ideas. They reflect the attitude of a personality to oneself. The first 9 scales form three main factors-modalities: selfaffirmation (self-management, self-confidence, reflected self-attitude, closedness); autosympathy (self-attachment, self-value, self-acceptance); self-destruction (inner proneness to conflict, selfaccusation). The results comparison in two groups according to each factor taking into account the level and the distribution of the compared feature was realized using nonparametric Fisher criterion of $\varphi$-angular transformation" [6].

The first four scales defined the factor of self-respect. It expressed the estimation of own "Self" by the individual from the point of view of social-normative criteria - purposefulness, will power, success, social approval, morality and etc.. In accordance with the mentioned criteria general "value" of self-respect was determined by high self-assessments, that is why during quantitative handling of results among both groups sten values were considered from two positions: low values (till 5,5 stens) and high values (more than 5,5 stens).

On the basis of the received empiric value of f-criterion ( $f_{e}=4,79$ in terms of $\left.f_{c r}=2,31, p=0,01\right)$ we rejected zero hypothesis about the absence of differences between the groups. We stated that in the main group high self-estimations (in terms of socially important criteria) are more often met, than in the control group.

The received result corresponds with the results of other scientists about the relative independence of self-respect factor and the factor of autosympathy [7]. The base for such correlational independence were the differences in the corresponding psychological traits orientation - if self-respect of a personality is defined, first of all, by the level of real "Self" correspondence with socially-desirable "Self" image, then the sense of disposition towards oneself doesn't provide such interconnection.

Thus, the results of the held psychodiagnostics research in two groups of athletes, who go in for different kinds of sport - fighting combats and athletic kinds of sport - help to describe both general traits and several specific features. They characterize self-attitude in athletes of different sports orientation.

For the athletes of both groups the following high indices are typical: personal self-sufficiency, prevalence of sympathy sense for oneself in a form of "friendly self-acceptance", satisfaction with own current state of development, the absence of neurotization features in a form of extreme selfaccusation.

As a result of the fulfilled comparative analysis of the answers in the group of athletes, who go in for fighting combats, we defined the following distinctive features of self-attitude: self-confidence, the developed qualities of self-management in different spheres of personal self-realization, low level of in intrapersonal conflictness and ambivalence.

For the group of athletes, who go in for athletic kinds of sport, it is typical to have psychological openness in a form of readiness to confess own negative drawbacks and qualities. The received results prove that the athletes of athletic kinds of sport have more developed sense of selfassessment. High risk of personal ambivalence and its unsteadiness in socially important situations is conditioned by the predominance of emotional component in the structure of own values experience. The indices of inner conflictness have higher values in comparison with the same indices of the main group and are statistically valid.

\section{CONCLUSION}

The held qualitative analysis of the athletes' answers gave an opportunity to describe psychological content of different aspects of self-attitude. According to the parameter of selfconfidence (during self-estimation) athletes gave the first place to reliability and self-respect. The representatives of fighting combats gave the first 
place to the ability to take responsibility and making decisions in difficult situations.

Secondary factors analysis showed that in athletes, who go in for fighting combats, productive structure of self-attitude prevails. Thus, this group is characterized by high indices of self-respect, based on athletes' high self-assessment according to socially important criteria. If we speak about low indices of "self-destruction", taking into account that they were received in terms of high argumentation, we can mention that they prove psychological correspondence between different aspects of outer and inner life of athletes, who go in for fighting combats.

\section{REFERENCES}

1. Vostroknutov S.I., Kuznetsov V.V.
Interconnection between motivations of professional pedagogical activity and reflexive skills development among the future physical culture teachers. Fizicheskaya kul'tura: vospitanie, obrazovanie, trenirovka. 2008; 6: 57-60 [In Russ.]. 2. Glass G., Stanley J. Statisticheskie metody v pedagogike I psihologii [Statistical methods in education and psychology]. Progress. 1976: 496 [In Russ.].

3. Kuznetsov V.V. Psychological analysis of athletes' subjective-personal features demonstration as the index of success of their activity (by the example of athletic kinds of sport and fighting combats). Candidate's thesis. Kazan. 2004: 171.

4. Likesh I., Lyaga Y. Oshnovnye tablitsy matematicheskoj statistiki [The main tables of mathematical statistics]. Moscow: Finances and statistics. 1985: 356 [In Russ.].

5. Pantileev S. P. Metodika issledovaniya samootnosheniya [Methodology of self-attitude study]. Moscow : "SMYSL". 1993: 32 [In Russ.].

6. Sidorenko E. V. Metody matematicheskoj obrabotki v psihologii [Methods of mathematical handling in psychology]. Saint-Petersburg: Socialpsychological center. 1996: 350 [In Russ.].

7. Stolin V.V. Samosoznanie lichnosti [Selfconscience of a personality]. Moscow: Moscow University publishing house. 1983: 284 [In Russ.].

8. Cleary T. Vitality, Energy, Spirit: A Taoist Sourcebook. Boston: Shambhala Publications. 1991. 9. Ormel J., Sanderman R., Steward R., Personality as modifier of the life event-distress relationship: A longitudinal structural education model. Person. Individ. Diff. 1988; 9(6): 973-982.

10. Pavel S. Sokolov, Tatyana V.Fendel. Physical fitness analysis in the members of special convoy units of Federal Penitentiary Service of Russia in Perm region. Pedagogiko-psihologicheskie I medico-biologicheskie problemy fizicheskoj kul'tury I sporta $=$ Russian Journal of Physical Education and Sport. 2019; 14(4): 91-96. DOI: 10.14526/20704798-2019-14-4-91-96 [In Russ., In Engl.].

11. Aleksandr S. Kuznetsov, Zinaida M. Kuznetsova. II Congress of members of the public organization «Russian professorial Assembly». Pedagogiko-psihologicheskie I medicobiologicheskie problemy fizicheskoj kul'tury I sporta $=$ Russian Journal of Physical Education and Sport. 2019; 14(4): 5-7. DOI: 10.14526/2070-4798-201914-4-5-7 [In Russ., In Engl.].

12. Gould D., Dieffenbach K., Moffett A. Psychological characteristics and their development in Olympic Champions. Journal of Applied Sport Psychology. 2002; 14: 172-204.

13. Jones M.V., Lane A.M., Bray S.R., Uphill M., Catlin J. Development and validation of the sport emotion questionnaire. Journal of Sport and Exercise Psychology. 2005; 27: 407-431.

14. Jones M.V., Meijen C., McCarthy P.J., Sheffield D. A theory of challenge and threat states in athletes. International Review of Sport and Exercise Psychology. 2009; 2: 161-180.

\section{Submitted: 15.03.2020}

Author's information:

Valentin V. Kuznetsov - Candidate of Psychological Sciences, Chaykovskiy State Institute of Physical Culture”, 6170oo, Russia, Chaykovskiy, Lenin str., House 67, e-mail: d.inga@inbox.ru

Svetlana N. Tregubova - Candidate of Pedagogics, Associate Professor, Chaykovskiy State Institute of Physical Culture", 61700o, Russia, Chaykovskiy, Lenin str., House 67, e-mail: lana20016@yandex.ru 